\title{
EXTERNAL DACRYOCYSTORHINOSTOMY IN PAEDIATRIC PATIENTS AND SURGICAL OUTCOMES- OUR EXPERIENCE IN A GOVERNMENT TEACHING HOSPITAL
}

\author{
Raman Yenugandula1, Prameela ${ }^{2}$, Anand Kumar ${ }^{3}$
}

${ }_{1}^{1}$ Associate Professor, Department of Ophthalmology, S. D. Eye Hospital, Hyderabad, Telangana, India.

${ }^{2}$ Assistant Professor, Department of Ophthalmology, S. D. Eye Hospital, Hyderabad, Telangana, India.

${ }^{3}$ Assitant Professor, Department of Ophthalmology, S. D. Eye Hospital, Hyderabad, Telangana, India.

\section{ABSTRACT}

\section{BACKGROUND}

In paediatric group patients, management of Epiphora is a stepwise process starting with probing at the age of 9-12 months and it results in high cure rates. For persistent watering and discharge following repeated probing, more invasive procedures like Balloon Dacryocystoplasty or external and endonasal Dacryocystorhinostomy are required in older children.

Our study was designed to evaluate the indications, intra operative events and surgical outcomes of external dacryocystorhinostomy in children.

Design- A descriptive study was carried out in the Department of Paediatric Ophthalmology at Sarojini Devi Eye Hospital including children undergoing external Dacryocystorhinostomy in the year 2017 with a minimum Post Op follow up of six months.

\section{MATERIALS AND METHODS}

The children aged between 7-14 years attending the OPD of Paediatric Ophthalmology were recruited for study numbering 50. The data collected regarding age, sex of the patients, side of the obstruction, indication for surgery, intra operative events, follow up period, post-operative complications and post-operative results. In our study, follow up period was at least 6 months. Data of the 50 patients are statistically analysed and presented.

\section{RESULTS}

In our study, the mean followup period was 8.78 months and age of the patients ranges from 7 years to 14 years with a mean of 8.71 years. The complication rate is low as successful outcomes seen in 47 cases (94\%) against failed patency in two cases (4\%) and in $2 \%$ cases there is partial patency resulting in occasional watering.

Incidence in males was slightly higher (60\%) than in females (40\%).

\section{CONCLUSION}

External DCR is a cost effective and efficient surgical treatment for Congenital NLDO or acquired lacrimal obstruction causing epiphora in children.

\section{KEY WORDS}

Congenital Nasolacrimal Duct Obstruction, External Dacryocystorhinostomy, Endonasal Dacryocystorhinostomy, Paediatric.

HOW TO CITE THIS ARTICLE: Yenugandula R, Prameela, Kumar A. External dacryocystorhinostomy in paediatric patients and surgical outcomes- our experience in a government teaching hospital. J. Evolution Med. Dent. Sci. 2018;7(45):4829-4833, DOI: $10.14260 /$ jemds/2018/1076

\section{BACKGROUND}

In the Paediatric age group patients, epiphora resulting from congenital nasolacrimal duct obstruction is a common problem. Epiphora affects nearly $20 \%$ of neonates. ${ }^{[1]}$

Children less than 1 year of age are cured of tearing in $96 \%$ of them with the help of conservative line of treatment.[1]

Different treatment modalities are tried in infants especially the topical antibiotic eye drops, digital massage to create hydrostatic pressure over the lacrimal passages in neonates below 9 months of age.

'Financial or Other Competing Interest': None.

Submission 21-09-2018, Peer Review 18-10-2018,

Acceptance 25-10-2018, Published 05-11-2018.

Corresponding Author:

Dr. Raman Yenugandula,

Associate Professor,

Department of Paediatric Ophthalmology,

S. D. Eye Hospital, Hyderabad,

Telangana, India.

E-mail: drraman33@gmail.com

DOI: $10.14260 /$ jemds/2018/1076
Neonates aged around 9 to 10 months are taken for nasolacrimal probing as it offers high cure rates but with increasing age the success rate may be reduced. $[2,3,4]$

Generally, if obstruction is at the level of Hasner's valve, probing leads to good outcomes. In the older children the obstruction may be at the lacrimal sac-lacrimal duct intersection which results in poor outcomes after nasolacrimal probing. ${ }^{[5]}$

Generally nasolacrimal intubation is recommended when epiphora persists even after two probings. ${ }^{[6]}$

This procedure yields good results $(80 \%$ of resolution and symptomatic improvement) if performed in children to resolve watering after two unsuccessful lacrimal probings.[7]

For persistent epiphora following probing, needs more intensive procedures like intubation, balloon dacryoplasty and external dacryocystorhinostomy.

The above-mentioned procedures are widely practiced.

Recent advances like endonasal dacryocystorhinostomy are added in the management strategies.[6]

But still in the majority of the Tertiary Care Eye Hospitals run by the government, charity hospitals and hospitals run by the individual ophthalmologists because of cost constraints, External Dacryocystorhinostomy is the preferred procedure. 
This procedure needs less instrumentation and at the same time success rates are high. Our Study is designed to evaluate the intra operative complications surgical time and surgical outcomes of external DCR in paediatric patients at a tertiary care government medical college eye hospital.

\section{MATERIALS AND METHODS}

This descriptive study was conducted in the department of paediatric ophthalmology at Sarojini Eye Hospital, Hyderabad, Telangana State, India after getting approval from the institutional medical ethics committee. Our study was conducted between Jan 2017 to February 2018.

Consecutive cases of congenital dacryocystitis with different clinical profiles like dacryocele, mucocele and lacrimal fistula were taken.

The inclusion criterion in the above mentioned clinical cases was patients aged between 7-14 years.

Acquired causes of epiphora like facial trauma are excluded from the study.

The follow up post-operative schedule is first post op day, first week, first month, 3 months and 6 months. All cases have completed a minimum follow up of six months.

Each time we have concentrated on the symptoms like watering and signs like inflammation in the wound area.

Lacrimal syringing was carried out to assess the patency of the rhinostomy tract.

Data of all patients aged less than 14 years included in the study was analysed.

Regarding age, sex, clinical presentation, intra operative events, surgical time, post-operative results like patency, cure of symptoms, reported complications and patient satisfaction were considered in the study.

The criteria for the success of surgery were disappearance of tearing, discharge and the resolution of lacrimal mucocele in addition to patent lacrimal passages on syringing.

All patients included in the study were taken for external DCR under general anaesthesia. For all the cases, ENT surgeon's opinion was taken pre-operatively to rule out clinical conditions like nasal polyps, rhinitis and deviated nasal septum.

One day prior to surgery, patients were kept on nasal decongestant drops and systemic antibiotics.

We especially investigated all the cases for bleeding disorders by obtaining clotting time and bleeding time and also obtained fitness from the anaesthesiologists.

standard surgical technique of external DCR was performed in all the patients by 3 surgeons (YR, AK, RP).

An incision of $1.5 \mathrm{~cm}$ length was marked over the anterior lacrimal crest extending $4 \mathrm{~mm}$ above and $10 \mathrm{~mm}$ below in a curvilinear fashion, $3 \mathrm{~mm}$ away from the medial canthus. (Fig. $1 \& 2$ )

The nasal mucosa was anaesthetised, and vasoconstrictor applied by placing the nasal pack which is soaked with the above medicines.

Fifteen minutes before start of surgery, Ethamsylate intra muscular injection was given which will help in controlling intra operative bleeding.
Once the skin incision is created, the Orbicularis muscle fibres were separated with blunt dissector and periosteum is exposed overlaying the anterior lacrimal crest and also above and below.

We used Mullers Self retaining Haemostatic Retractor and Catpaw Retractors to expose the lacrimal sac and the floor. ${ }^{[8]}$

Lacrimal sac is retracted laterally with the help of sac retractor and periosteum is dissected off the floor of the lacrimal sac and as well as lacrimal bone.

Meanwhile we maintain strict haemostasis to visualize the structures.

The osteotomy is created in the floor of lacrimal sac mainly in the thin lamina papyracea and the bone punch is used for the purpose.

Once the osteotomy is created it is enlarged to the size of nearly 9-10 $\mathrm{mm}$ in diameter.

During the entire procedure to maintain visualization of the structures, suction cannula is used to prevent pooling of blood in the event of bleeding. (fig.3)

More frequently we used cottonoids and packing to control capillary bleeding.

Osteotomy is made between anterior and posterior lacrimal crests and nasal mucosa is identified.

The Nasal mucosa is opened by a h shaped incision and both anterior and posterior flaps are created. next we come to negotiate the lacrimal sac, a vertical incision is made along the entire length of fundus and body, any contents are evacuated.

In our procedures we partially excised both posterior flaps of the lacrimal sac and nasal mucosa.

Both the anterior flaps of the lacrimal mucosa and nasal flaps are sutured by using interrupted 6'0 vicryl sutures (fig4). after completing the flap suturing, orbicularis muscle fibres closed with 6'0 vicryl sutures (fig-5) and also the skin flaps. (fig. 6)

In two cases we used silicon tubes to intubate the lacrimal passage system.

Silicon tubes were tied together with $6^{\prime} 0$ prolene and sutured to the lateral nasal wall.

These tubes were removed after four weeks. for rest of all cases no intubation was done.

Immediate post op day along with wound dressing lacrimal syringing was done. post op followup was according to the prescribed follow up schedule.

In the post op day topical anti biotic drops are prescribed for a period of 1 month and systemic antibiotics given for one week.

Nasal decongestant drops for instillation and systemic anti-inflammatory drugs prescribed for five days.

Patients' attendants were clearly explained not to blow the nose with an instruction of emergency visit to the hospital in case of Bleeding from the nose on the operated side.

All the cases have completed a minimum follow up of 6 months from the day of surgery.

The data of the cases was collected and subjected to statistical analysis using Microsoft Office and presented in the study. 


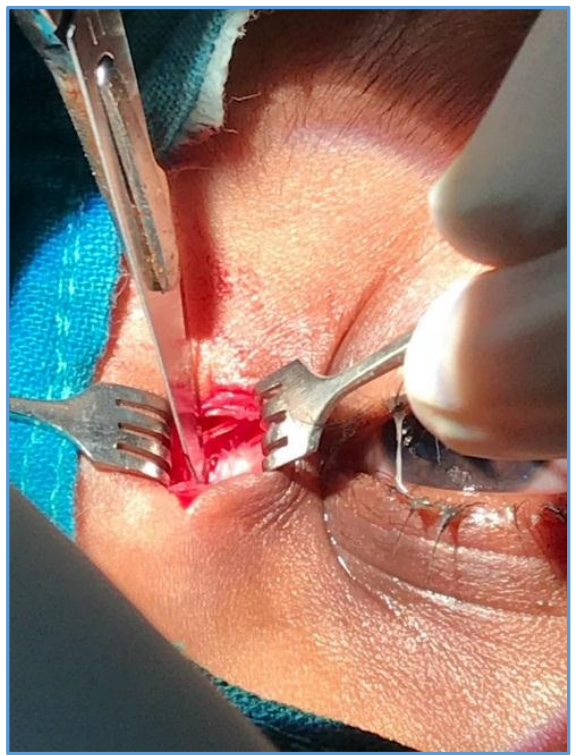

Figure 1. Identification and Dissection of the Medial Palpebral Ligament exposes Lacrimal Sac

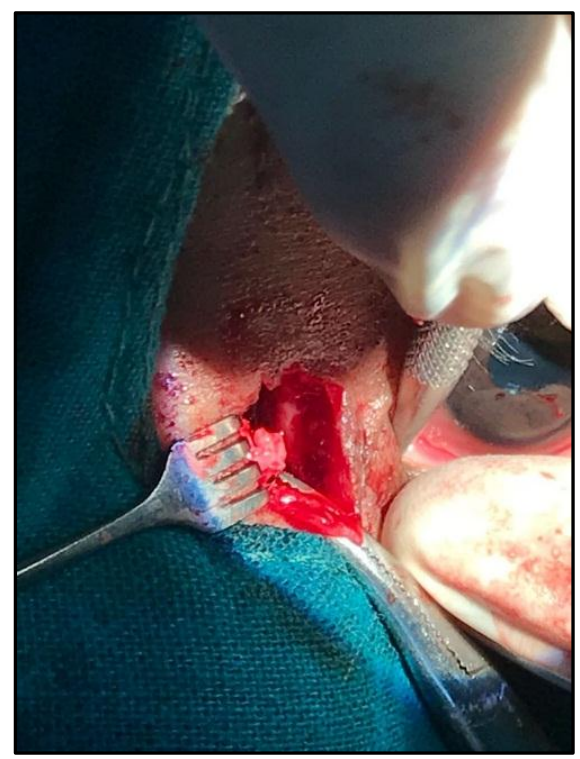

Figure 2. Preparation of the Anterior Flaps of Lacrimal Sac and Nasal Mucosa

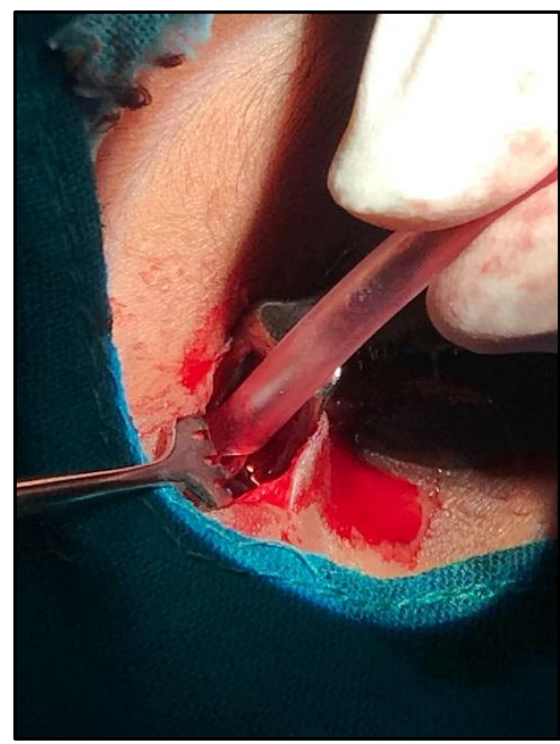

Figure 3. Suction Cannula used to prevent Pooling of Blood

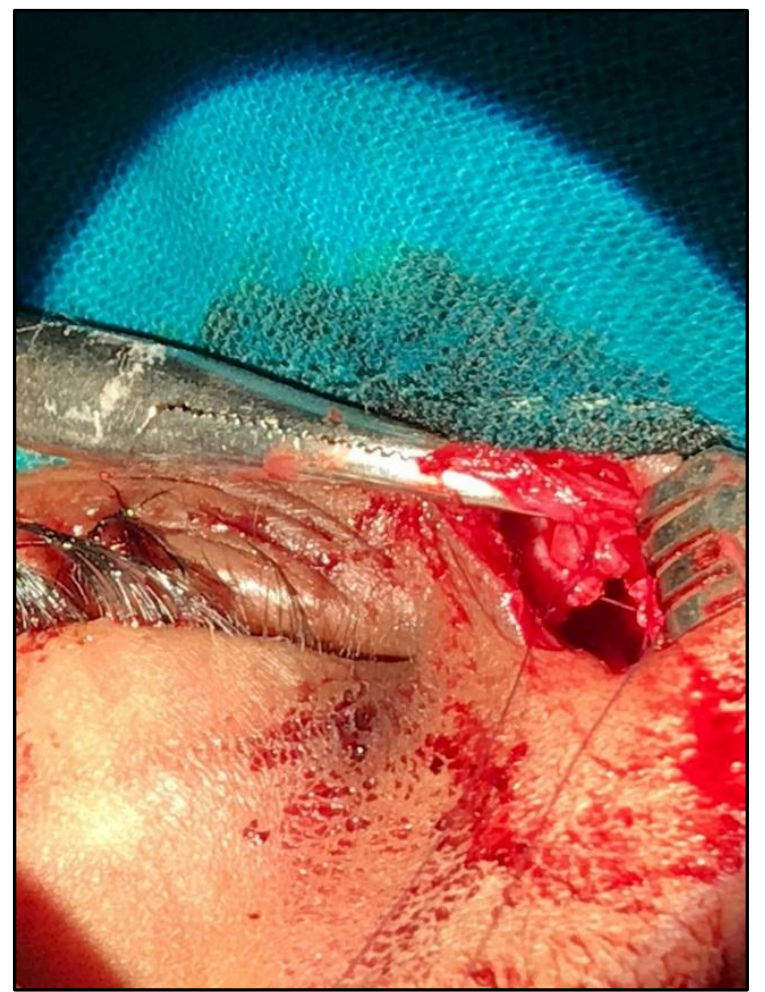

Figure 4. Interrupted Vicryl Sutures used for Anastomosis of the Anterior Flaps

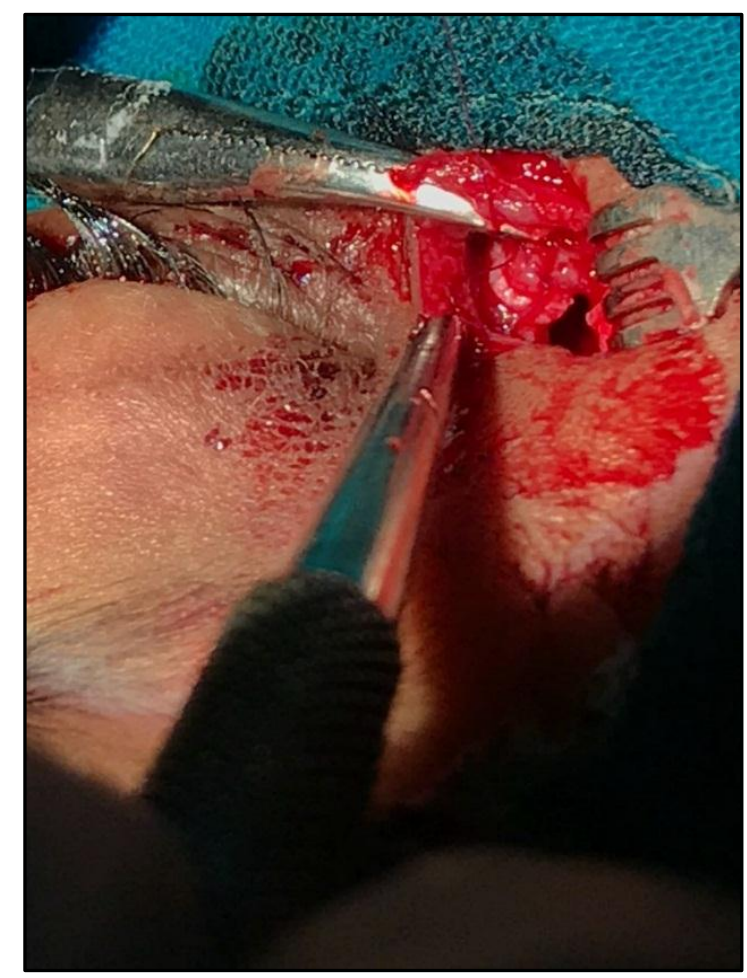

Figure 5. Suturing of the

Orbicularis Muscle Fibres 


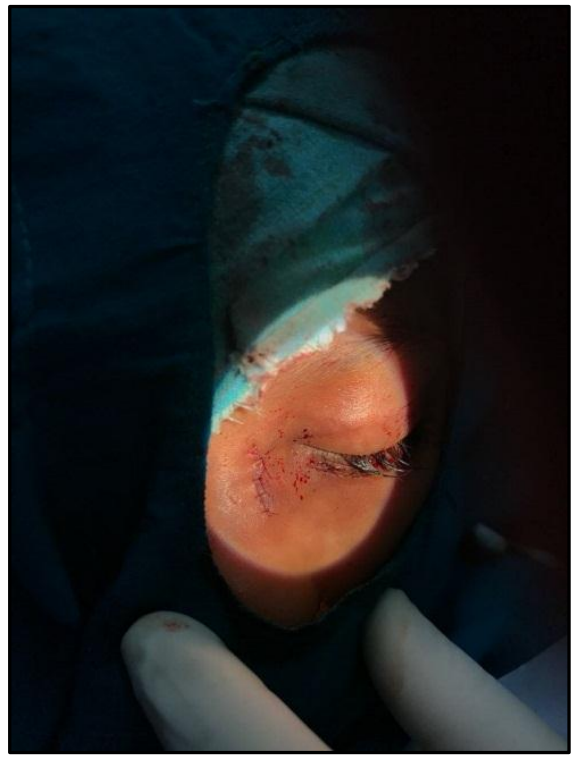

Figure 6. Skin Closure with Vicryl Sutures

\section{RESULTS}

The demographic characteristics of all patients, clinical profiles, Intra operative complications, surgical time and post-operative results are shown in the different tables.

\begin{tabular}{|c|c|c|}
\hline No.1 & Failed Probing Cases of Congenital NLDO & 25 \\
\hline No.2 & Congenital NLDO without Prior Probing cases & 9 \\
\hline No.3 & Lacrimal Mucocele & 4 \\
\hline No.4 & Lacrimal Fistula & 2 \\
\hline No.5 & Acquired Dacryocystocele & 10 \\
\hline \multicolumn{3}{|c|}{ Table 1. Indications for External DCR } \\
\hline
\end{tabular}

\begin{tabular}{|c|c|c|}
\hline Age (In Years) & Sex - Male & Sex - Female \\
\hline Range & $7-12$ Years & $7-14$ Years \\
\hline Mean \pm SD & $8.23 \pm 1.39$ & $9.18+1.98$ \\
\hline Sex of the Patients (\%) & & \\
\hline Males & 30 Males $(60 \%)$ \\
\hline Females & 20 Females $(40 \%)$ \\
\hline Operated Side (\%) & \\
\hline Right Side & $29(58 \%)$ \\
\hline Left Side & $21(42 \%)$ \\
\hline Follow Up Period & $6.5-14.5$ Months \\
\hline Range & $8.78 \pm 1.98$ \\
\hline Mean \pm SD & Table 2. Demographic Data \\
\hline \multicolumn{2}{|c|}{}
\end{tabular}

\begin{tabular}{|c|c|c|c|}
\hline No & $\begin{array}{c}\text { Intra Operative } \\
\text { Complications }\end{array}$ & $\begin{array}{c}\text { No. of } \\
\text { Cases }\end{array}$ & $\begin{array}{c}\text { Surgical } \\
\text { Time }\end{array}$ \\
\hline No.1 & Intra Operative Excess Bleeding & $3(6 \%)$ & 1 hour \\
\hline No.2 & Loss of Nasal Mucosa & $2(4 \%)$ & 50 mins \\
\hline No.3 & $\begin{array}{c}\text { Ruptured Lacrimal Sac and } \\
\text { Partial Loss of Mucosa }\end{array}$ & $2(4 \%)$ & 50 mins \\
\hline \multicolumn{4}{|c|}{ Table 3. Intra Operative Complications and Surgical Time } \\
\hline
\end{tabular}

\begin{tabular}{|c|c|}
\hline Successful Outcomes & 47 cases (94\%) \\
\hline Failed patency & $2(4 \%)$ \\
\hline $\begin{array}{c}\text { Patency present with } \\
\text { occasional discharge }\end{array}$ & $1(2 \%)$ \\
\hline
\end{tabular}

In our Study, the mean followup period was 8.78 months and age of the patients range from 7 years to 14 years with a mean of 8.71 years. Male children are more $(60 \%)$ than female patients (40\%). the distribution of patients regarding the side of obstruction is right side (58\%) and left side (42\%). the complication rate is low as successful outcomes seen in 47 cases (94\%) against failed patency in two cases (4\%) and in $2 \%$ cases there is a partial patency resulting in occasional watering.

\section{DISCUSSION}

All the cases presented to us were having persistent watery discharge, some of them even after having repeated lacrimal probing. These cases were taken for external DCR at the least age of 7 years. At our institute, we are not practicing lacrimal intubation because of lack of facilities.

Balloon dacryoplasty is again emerging as a new modality in children aging more than 1 year but results are still controversial.[8,9]

DCR in the paediatric patients is not as predictable as in adults. In children, anatomy of the lacrimal passage is immature and rapidly changing along with a tendency towards vigorous scar tissue growth and closure of the osteotomy.

But adequate osteotomy and good anastomosis yields best results.

Anastomosis must be tension free and adequate. External DCR results in obvious cutaneous scar, when compared with endonasal DCR. the endo DCR is not preferred choice in view of small anatomical dimensions especially the sac and the nasal cavity which hinder easy performance of the procedure, still we need more reports regarding success of endo DCR.

In addition, clinical cases like congenital NLDO, lacrimal mucocele and lacrimal fistula need external DCR. endo nasal DCR with or without assisted laser needs costly instrumentation and additional training, which may not be affordable in certain institutions. Our main objective of this study is to show the good surgical outcomes using least and cost effective instrumentation.

In our study, the majority $(80 \%)$ of cases belong to congenital in nature, including NLDO, lacrimal mucocele and lacrimal fistula.

In a study in Nigeria, $88 \%$ had congenital NLDO and only $18 \%$ had post traumatic lacrimal obstruction.

A Study in Nepal reported the acquired NLDO 63\% of cases. Marr and colleagues [10-12] in their study reported $92 \%$ of patients had congenital NLDO and only $8 \%$ acquired cases, which is nearly close to our study.

In our study, $68 \%$ of cases belong to congenital NLDO with or without prior lacrimal probing and $4 \%$ of cases belong to Lacrimal fistula and $8 \%$ of cases belong to Mucocele.

In this study, external DCR was performed in $50 \%$ of cases of failed lacrimal probing and $18 \%$ of cases are previously managed conservatively. the present study achieved overall success rate of $94 \%$.

Abdu and Salisu[10] reported $88 \%$ of success rate of external DCR in children with 1 year post op follow up.

Nowinski et al[13] reported $83 \%$ as an overall success rate and Hakin et al[14] claimed $96 \%$ in patients without canalicular problems and $79 \%$ in patients with canalicular problems. 
Shrestha et al[11] reported $96 \%$ success rate, while Barnes et al[15] from Nepal reported $97 \%$ success rate although their patients had acquired causes of epiphora.

Maheshwari reported $97.5 \%$ success ${ }^{[16]}$ which matched the results of Mohammad F. Khalil, Sahar T et al in the congenital sub group with congenital NLDO after failed probing and intubations.[17]

Regarding the intra operative events we had partial loss of sac mucosa (4\%) and loss of nasal mucosa in two cases (4\%) and excessive bleeding in $6 \%$ cases.

In case of loss of nasal mucosa lacrimal flap mucosa is sutured to the periosteum reflected from the anterior lacrimal crest and lacrimal bone.

On and average in majority cases, entire surgical time was around 40 minutes. In one case of excess intra operative bleeding out of 3 cases, the surgery time prolonged to 1 hour.

The complications like loss of nasal mucosa and partial loss of sac wall have prolonged surgical time to around 50 minutes.

Few post-operative complications like bleeding from the nose in one case $(2 \%)$ and peri orbital oedema in another case $(2 \%)$ were managed effectively.

The surgical technique used in this series established an immediate mucosa lined fistula between the lacrimal sac and middle turbinate of the nose. In our series, in two cases we used silicon tubes for intubation. They were removed after 4 weeks but in no case skin sutures were removed.

External DCR is an effective procedure in children can be performed comfortably in less than 1-hour time.

With the increase in surgeon's experience, surgical volume, meticulous pre-operative preparation, the surgical time can be reduced.[18]

Our study definitely confirms this fact. There is complete disappearance of watering and discharge observed in $94 \%$ of cases and most patient attendants (parents) expressed satisfaction.

The instrumentation and supply cost of endonasal DCR with or without assisted laser may be prohibitive factor in cost constrained hospitals.

In this article, our study confirms that external DCR is an effective and highly successful procedure with little risk of recurrence, postop bleeding and unacceptable skin scar. However, it is a short-term study. In the future, a greater number of studies should focus on comparative evaluation of external DCR and endonasal DCR. In our study, regarding surgical technique, we left posterior flaps (nasal mucosa and sac mucosa) unsutured after partial excision to cut down the surgical time, however we achieved good patent lacrimal passages. No other study focused on this surgical aspect.

\section{CONCLUSION}

External DCR is a cost effective and efficient surgical treatment of congenital NLDO or acquired lacrimal obstruction causing epiphora in children.

\section{REFERENCES}

[1] MacEwen CJ, Young JD. Epiphora during the first year of life. Eye (Lond) 1991;5(Pt 5):596-600.
[2] Robb RM. Success rates of Nasolacrimal duct probing at time intervals after 1 year of age. Ophthalmology 1998;105(7):1307-9, discussion 1309-10.

[3] Mannor GE, Rose GE, Frimpong-Ansah K, et al. Factors affecting the success of nasolacrimal duct probing for congenital nasolacrimal duct obstruction. Am J Ophthalmol 1999;127(5):616-7.

[4] Sturrock SM, MacEwen CJ, Young JD. Long-term results after probing for congenital nasolacrimal duct obstruction. Br J Ophthalmol 1994;78(12):892-4.

[5] Kushner BJ. The Management of Nasolacrimal duct obstruction in children between 18 months and 4 years old. J AAPOS 1998;2(1):57-60.

[6] Tan AD, Rubin PA, Sutula FC, et al. Congenital nasolacrimal duct obstruction. Int Ophthalmol Clin 2001;41(4):57-69.

[7] Aggarwal RK, Mission GP, Donaldson I, et al. The role of nasolacrimal intubation in the management of childhood Epiphora. Eye (Lond) 1993;7(Pt 6):760-2.

[8] Gunton KB, Chung CW, Schnall BM, et al. Comparison of balloon dacryocystoplasty to probing as the primary treatment of congenital nasolacrimal duct obstruction. J AAPOS 2001;5(3):139-42.

[9] Yuksel D, Ceylan K, Erden O, et al. Balloon dilatation for treatment of congenital nasolacrimal duct obstruction. Eur J Ophthalmol 2005;15(2):179-85.

[10] Abdu L, Salisu AD. Pattern and outcome of surgical management of nasolacrimal duct obstruction in children: a five year review. Ann Afr Med 2014;13(3):130-3.

[11] Shrestha R, Sobti D, Chi SL, et al. Surgical outcome of paediatric dacryocystorhonistomy in Nepal. J AAPOS 2014;18(4):368-9.

[12] Marr JE, Drake-Lee A, Willshaw HE. Management of childhood epiphora. $\mathrm{Br} \quad \mathrm{J}$ Ophthalmol 2005;89(9):1123-6.

[13] Nowinski TS, Flanagan JC, Mauriello J. Paediatric dacryocystorhonistomy. Arch Ophthalmol 1985;103(8):1226-8.

[14] Hakin KN, Sullivan TJ, Sharma A, et al. Paediatric dacryocystorhonistomy. Aust N Z J Ophthalmol 1994;22(4):231-5.

[15] Barnes EA, Abou-Rayyah Y, Rose GE. Paediatric dacryocystorhonistomy for nasolacrimal duct obstruction. Ophthalmology 2001;108(9):1562-4.

[16] Maheshwari R. External dacryocystorhonistomy in paediatric nasolacrimal duct obstruction. Asian J Opthalmol 2006;8:242-4.

[17] Khalil MF, Abdelrazik ST. External dacryocystorhonistomy in paediatric age group: indications and outcome results. Journal of Egyptian Ophthalmological Society 2015;108(2):57-60.

[18] Tarbet KJ, Custer PL. External dacryocystorhonistomy. Surgical success, patient satisfaction, and economic cost. Ophthalmology 1995;102(7):1065-70. 